\title{
BEYOND BULLDOZING HABITS OF MIND
}

\begin{abstract}
Almantas SAMALAVIČIUS
I must admit that four years ago while accepting an invitation to edit the journal I had a vague idea of where it will take me and my co-workers. A few weeks after I finally agreed to take over as editor-in-chief of this publication I was quite unexpectedly faced with a task of reshaping a national research journal that had its own local history and importance into an international scholarly quarterly. Time spent while building up the journal's new international profile and format has been extremely interesting and challenging in many ways and my thanks are due to internationally renowned architects, urban designers, architectural and urban scholars who have agreed to serve on the journal's editorial board and a large (and still growing) number of reviewers who have given and continue to give their time for assessing the quality of numerous submissions. Contrary to what I expected initially it was not always easy to launch guest-edited issues especially during the last year. We had to cancel an issue initially focused on Knowing by Designing as its guest editor who suggested us the thematic scope unexpectedly vanished and my attemtpts to reach him repeatedly by mail ended in no result. Nevertheless I do hope he is otherwise doing well. There have been some more changes recently: we won't be publishing an issue focused on Empathic Architecture this year albeit for technical reasons only and I do hope our readers will be able to browse the issue early next year when the delayed peer-review process is over.

This issue is coming out as regular instead of being thematically oriented. A closer reading of the material presented will, however, convince the readers that the articles submitted independently and without a focus on any special issue still contain some common ground. I must admit that I am quite happy that this journal presents submissions coming from authors residing in many parts of the world and we have been

open to so many articles providing insight into a wide range of geographical locations and different cultural settings. This issue is no exception. Authors writing from seemingly different locations: Canada, Turkey, Saudi Arabia, UAR, and Iran seem to share some common concern about what makes our existence in contemporay urban environment complex, complicated and often problematic. As an editor of this journal I have pursued a policy of not being an Eurocentric and though the journal is being edited in east central part of Europe it covers a variety of issues coming from non-European locations. While editing the articles of this issue for publication I was stimulated to go back to some extremely insigtful observations of our more and more globalised urban environments that seem to share the same problems even if their local forms are somewhat varied. Contemplating on the urban development of the last century in his concise volume of essays published more than a half century ago the renowned architectural and urban critic Lewis Mumford observed that "Perhaps our age will be known to the future historian as the age of bulldozer and the exterminator; and in many parts of the country the building of a highway has about the same result upon vegetation and human structures as the passage of tornado or the blast of an atom bomb. Nowhere is this bulldozing habit of mind so disastrous as in the approach to the city. Since the enginner regards his own work as more important than the other human function it serves, he does not hesitate to lay waste to woods, streams, parks, and human neighborhoods in order to carry his roads straight to their supposed destination." And though tornadoes have become more commonplace in this century because of persistent climate change and our curious inability to respond adequately, Mumford's observation on the habits of mind dominating in the sphere of urbanism remains as insigthul as it was a half century ago.
\end{abstract}

